\title{
ICESat GLAS Elevation Changes and ALOS PALSAR InSAR Line-of-Sight Changes on the Continuous Permafrost Zone of the North Slope, Alaska
}

\author{
Reginald R. Muskett \\ Geophysical Institute, University of Alaska Fairbanks, Fairbanks, AK, USA \\ Email: reginald.muskett@gmail.com
}

Received 17 August 2015; accepted 17 October 2015; published 20 October 2015

Copyright (C) 2015 by author and Scientific Research Publishing Inc.

This work is licensed under the Creative Commons Attribution International License (CC BY). http://creativecommons.org/licenses/by/4.0/

(c) (i) Open Access

\begin{abstract}
Measuring centimeter-scale and smaller surface changes by satellite-based systems on the periglacial terrains and permafrost zones of the northern hemisphere is an ongoing challenge. We are investigating this challenge by using data from the NASA Ice, Cloud, and land Elevation Satellite Geoscience Laser Altimeter System (ICESat GLAS) and the JAXA Advanced Land Observing Satellite Phased Array type L-band Synthetic Aperture Radar (ALOS PALSAR) on the continuous permafrost zone of the North Slope, Alaska. Using the ICESat GLAS exact-repeat profiles in the analysis of ALOS PALSAR InSAR Line-Of-Sight (LOS) changes, we find evidence of volume scattering over much of the tundra vegetation covered active-layer and surface scattering from river channel/banks (deposition and erosion), from rock outcropping bluffs and ridges. Pingos, ice-cored mounds common to permafrost terrains can be used as benchmarks for assessment of LOS changes. For successful InSAR processing, topographic and tropospheric phase cannot be assumed negligible and must be removed. The presence of significant troposphere phase in short-period repeat interferograms renders stacking ill suited for the task of deriving verifiable centimeter-scale surface deformation phase and reliable LOS changes.
\end{abstract}

\section{Keywords}

ICESat, GLAS, ALOS, PALSAR, Permafrost, Alaska

\section{Introduction}

Satellite-based interferometric SAR (InSAR) needs at least two data acquisitions by orbital passes over the re-

How to cite this paper: Muskett, R.R. (2015) ICESat GLAS Elevation Changes and ALOS PALSAR InSAR Line-of-Sight Changes on the Continuous Permafrost Zone of the North Slope, Alaska. International Journal of Geosciences, 6, 1101-1115. 
gion of interest of the surface of the Earth [1]-[8]. The data acquisitions, i.e. backscatter in two-way travel times of the radar form granules (a.k.a. scenes) in slant range and azimuth (minimum values form the pixel, i.e. resolution cell) along the orbit path (a space-based Mercator projection system with the Earth center of mass as the center-of-figure of the projection system) [9]. For the two granules to form an interferogram with each fringe representing a 0 to $\pm 2 \pi$ (the $2 \pi$ ambiguity) phase difference a number of requirements must be satisfied [9]. They involve the sub-pixel geolocation accuracy and precision, a perpendicular baseline (repeat-pass orbit geometry in Line-Of-Sight) of the granule-pair being less than a critical value that depends on the SAR frequency and coherence of the differential interferometric phase within the pixels of the granule-pair [9]. Having met these requirements, an interferogram is produced containing phase information from the sum of coherent phase components from sources on the ground (topography, deformation [i.e. surface motion in horizontal and vertical coordinates]), volumetric (potentially depth of penetration beneath the ground surface, vegetation and snow thickness when present), atmosphere (tropospheric sources and total electron content and Faraday rotation) which all serve to alter the atmosphere optical path of the radar between acquisitions) and errors of the components [9]. Further processing with models of the components that are not of interest, such as a DEM to remove the topographic phase and to unwrap the interferogram, reveals changes along the Line-Of-Sight (LOS) vector that occurs between the SAR acquisition times. Interpretation of the LOS change therefore requires knowledge of geology, hydrology, land cover and meteorology.

Within the Earth's periglacial terrains of the high latitudes there is seasonally frozen ground, i.e. the active layer, and the underlying perennially frozen ground, i.e. permafrost, ground with a mean annual temperature below $0^{\circ} \mathrm{C}[10]$ [11]. The high-latitudes of the northern hemisphere are especially noted for the permafrost zones: continuous, discontinuous and sporadic [10] [11]. Permafrost can be dry as is the case in parts of Greenland and Antarctica [10]. Where seasonal water is present as pore, interstitial and vapor there can be annual growth of ice as pore, interstitial and wedges (leading to ground ice) and giving rise to patterned ground landscapes of networks of high and low centered polygons from the seasonal expansion and contraction [10]. Seasonal thawing, melting and refreezing can lead to small motions at $\mathrm{mm}$ and $\mathrm{cm}$ scales, heave and subsidence, of the ground surface as ice-wedges grow or degrade and polygon interior-surfaces change from high to low and vice versa over a period of years [10].

Measuring the ground-patterns of such small-scale surface displacements and understanding their causes is an ongoing part of permafrost research [12]. These small-scale surface displacements can be measured accurately with very simple methods [12]. Scientists are now seeking answers as to how these patterns of surface changes can affect regional carbon, energy and water cycles. Therefore, a growing challenge is to perform a measuring process with the same accuracy as traditional methods and that can cover permafrost landscapes at the regional scale for assessment of linked forcing and feedback of recent and long-term climate change [13].

In this paper, we present results aimed at addressing this measurement challenge by using repeat-pass laser altimetry from the NASA Ice, Cloud and land Elevation Geoscience Laser Altimeter System mission and the JAXA Advanced Land Observing Satellite Phased Array type L-band Synthetic Aperture Radar. Our region of interest and testing lies on the North Slope of Alaska, the Anaktuvuk wildfire scar within the tussock tundra of the continuous permafrost zone and the Barrow peninsula on the coast of the Arctic Ocean, Figure 1.

\section{Data and Methods}

\subsection{NASA Ice, Cloud and land Elevation Geoscience Laser Altimeter Mission}

The NASA Ice, Cloud and land Elevation (ICESat) mission was launched in January 2003 from Vandenberg Air Force launch complex, California. The mission generated light detection and ranging global datasets for study of ice sheet, land and ocean surface changes, cloud-aerosol incidence and vegetation biomass properties [14]. The principal measurement instrument onboard ICESat was the Geoscience Laser Altimeter System (GLAS) [15]. GLAS utilized three lasers each with a green $(532 \mathrm{~nm})$ and red $(1064 \mathrm{~nm})$ channel. ICESat's $600 \mathrm{~km}$ altitude sun-synchronous polar orbit covered the Earth from $86^{\circ} \mathrm{N}$ to $86^{\circ} \mathrm{S}$ latitude in a period of 97 minutes or 14.8 orbits per day [15]. The original mission concept called from laser altimetry acquisitions (3 lasers) on 8- and 91day repeat cycles over the expected lifetime of 3-years. On day-38 of data acquisition in March 2003 Laser 1 (L1) experienced electronic failure (component degradation). After almost one year operation of Lasers 2 (L2) and 3 (L3) were rescheduled into roughly 30-day intervals within the 91-day repeat cycle to mitigate degradation and acquire the primary datasets of ice sheet surface elevation and changes relative to their mass-balance 


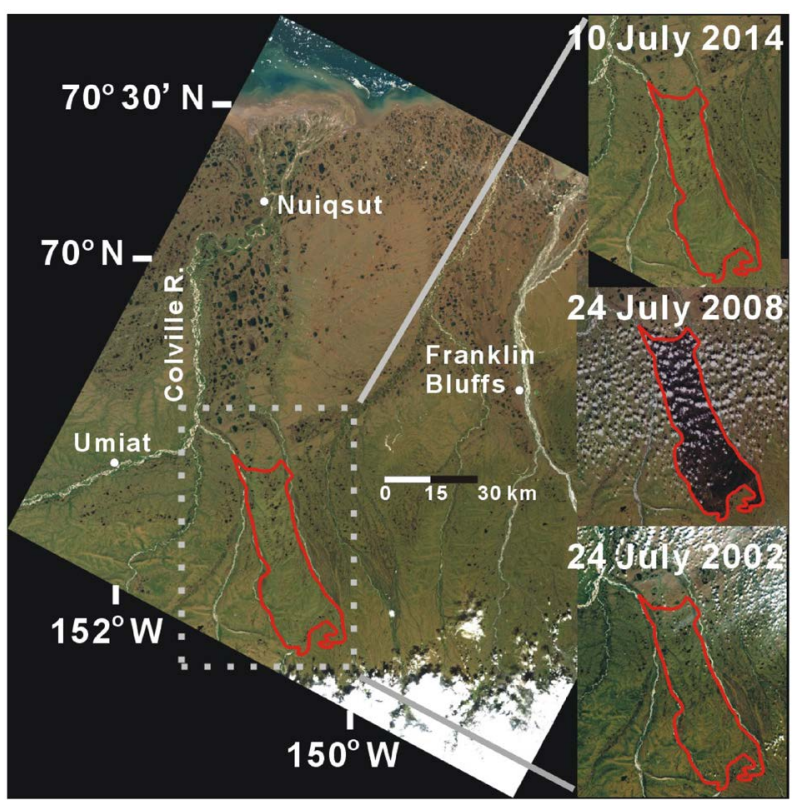

Figure 1. A region of interest on the North Slope, Alaska: The Anaktovuk Wildfire scar, as observed in LANDSAT7 and 8 images from 24 July 2002 (before the wildfire), 24 July 2008 (one year after the wildfire) and 10 July 2014 (showing vegetation recovery seven years after the wildfire).

cycles. This change of plan extended the data acquisition phase of the mission far beyond the original goal of 3-years. In early October 2009 the data acquisition phase of the mission ended with the failure of L2, which had been re-started after the failure of L3. ICESat was decommissioned in February 2010. Managed atmospheric reentry over the Pacific Ocean occurred in August 2010 1.

The GLAS lasers pulsed at 40-times per second at the $532 \mathrm{~nm}$ (atmosphere channel) and the $1064 \mathrm{~nm}$ (land elevation channel) [15]. The footprint diameter varied from about $60 \mathrm{~m}$ to $70 \mathrm{~m}$ in a nominal-circular area. Footprints were displaced from centroid-to-centroid by about $170 \mathrm{~m}$ along the surface-track. Onboard Global Positioning System (GPS) dual-JPL receivers with dual-channel capability, star-camera and retro-reflector cones (satellite laser ranging) provided for precise attitude, location, pointing and timing of the satellite and lasers. During the mission corrections to the GLAS data include orbit, atmosphere and tides and post-mission corrections include for timing, range drift and atmosphere (Table 1). This allows the ICESat instantaneous-inertial reference frame to the mapped to the International Terrestrial Reference Frame (ITRF). Calibration-validation campaigns during the mission show accuracy and precision better than $0.05 \mathrm{~m} \mathrm{[14]} \mathrm{[16].} \mathrm{Processing} \mathrm{and} \mathrm{refine-}$ ment continue post-mission with improvements of the error budget knowledge ${ }^{2}$.

For this investigation, Figure 2, we use the global elevation data GLA06 as in our previous investigations of glacier mass balance, frozen tundra-lake surface elevations (snow depth variations) and river-ice surface elevation variations forced by Laptev Sea tides (Table 2) [16]-[20]. For consistency checking we used GLA06 at versions 28 through 48 at quality levels 4 (previous) and 6 (current) for the GLAS campaigns L2 and L3, which constitute precise-repeat geolocaiton less than 5-meters of the footprint-to-footprint centroids. Geolocation is by World Geodetic System reference ellipsoid WGS-84 and elevation is by Earth Geopotential Model-1996 (EGM96) and consistent with ITRF Epoch $2010^{3}$.

\subsection{JAXA Advanced Land Observing Satellite Phased Array Type L-Band Synthetic Aperture Radar}

The JAXA Advanced Land Observing Satellite (ALOS) mission was launched in January 2006 from the Tane-

\footnotetext{
${ }^{1}$ http://en.wikipedia.org/wiki/Icesat.

${ }^{2}$ http://nsidc.org/data/icesat/past_releases.html.

${ }^{3}$ http://nsidc.org/data/docs/daac/glas_icesat 11_12 global_altimetry.gd.html.
} 


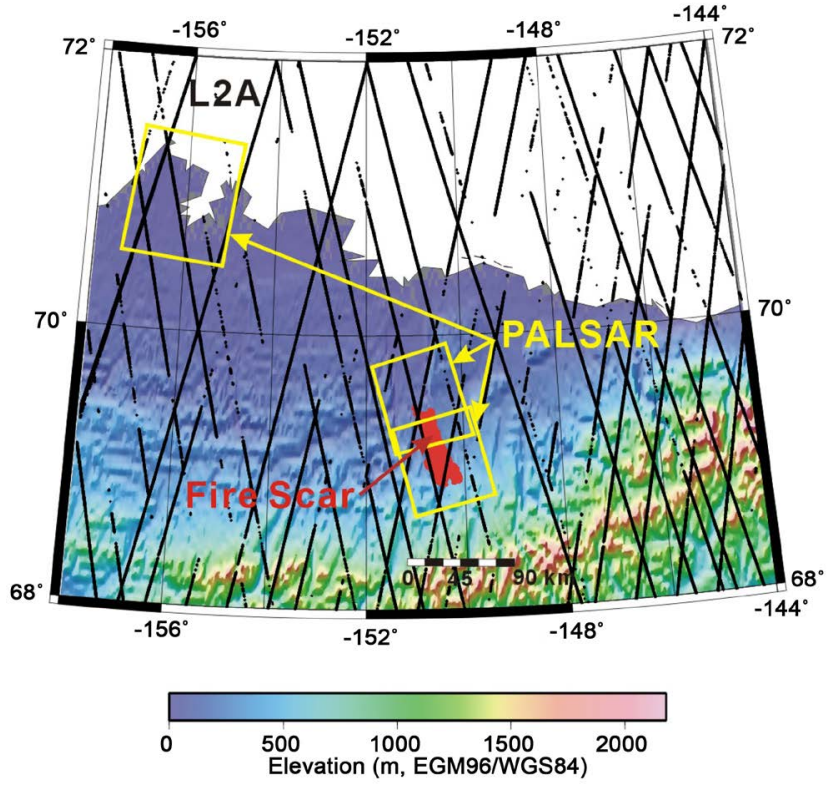

Figure 2. The region of the North Slope, Alaska, for the investigation showing the outline of the Anaktovuk wildfire scar (red outline) and datasets used. Black lines illustrate ICESat GLAS ground-tracks (Laser campaign 2D, L2D), ALOS PALSAR acquisitions (yellow boxes) with the Altimetry Corrected Digital Elevation Model version 2 (ACE2 DEM) as background.

Table 1. ICESat mission and post-mission processing corrections.

Mission Processing Corrections
Orbit-onboard GPS maps to ITRF
Spacecraft pointing knowledge (GPS, laser ranging and star tracker)
Atmosphere
Tides (solid, liquid and pole-tide effects)
Plate tectonic motion
Post-Glacial motion
Post-Mission Corrections
Correction for drift error in range determination due to transmit-pulse time centroid-Gaussian reference
Correction of pulse saturation data on Laser 3
Improved atmosphere calibration
Correction to precise attitude determination
Update to star tracker data

Table 2. ICESat GLAS exact-repeat track-pairs used for elevation change, anaktuvuk fire scar.

\begin{tabular}{cccc}
\hline Date & Campaign & PRKK & TTTT \\
\hline $10 / 27 / 2003$ & L2A & 2103 & 0081 \\
$03 / 05 / 2006$ & L3E & 2115 & 0081 \\
$11 / 15 / 2006$ & L3G & 2117 & 0238 \\
$04 / 02 / 2007$ & L3H & 2119 & 0238 \\
$11 / 14 / 2003$ & L2A & 2103 & 0357 \\
$11 / 23 / 2006$ & L3G & 2117 & 0357 \\
$11 / 22 / 2006$ & L3G & 2117 & 0349 \\
$12 / 12 / 2008$ & L2D & 2127 & 0349 \\
\hline
\end{tabular}

$\mathrm{P}=$ Repeat ground-track phase; $\mathrm{R}=$ Reference orbit number; KK = instance number, incremented for new reference orbit; TTTT = Track within reference orbit. 
gashima Space Center, Kyushu, Japan. ALOS carried three observation instruments, two electro-optical and one Synthetic Aperture Radar (SAR) for cartography, land cover classification and disaster monitoring ${ }^{4}$. The ALOS sun-synchronous polar orbit covered the Earth from $82^{\circ} \mathrm{N}$ to $82^{\circ} \mathrm{S}$ latitude in a period of 99 minutes or 14.6 orbits per day [21]. The product requirement of the mission called for providing user communities (cartography, geodesy, environment and resource monitoring) with panchromatic and multi-spectral and SAR datasets capable of producing 1:25,000 scale maps with $2.5 \mathrm{~m}$ horizontal resolution with 3-to-5 m vertical accuracy [21] [22]. The mission data acquisition lifetime was planned to be for 3-years with a goal of reaching 5-years. Data distribution was accomplished by continental-based intergovernmental agreements [23]. For North and South America (Americas ALOS Data Node) was facilitated by NOAA with the Alaska Satellite Facility, GeophysicalInstitute at the University of Alaska, Fairbanks [4]. In April 2011, a power failure occurred rendering communications inoperative. On 12 May 2011, JAXA retired ALOS operations and ended the mission.

The SAR instrument onboard ALOS is the Phase Array type L-band Synthetic Aperture Radar (PALSAR) developed by JAXA, Japan Resources Observation System Organization and the Ministry of Economy, Trade and Industry [21]-[24]. The ALOS PALSAR and orbit constraints were designed to be the first space-borne L-band SAR capable of globally monitoring slow crustal deformation, i.e. types of creep and accumulated small displacements along and lateral to a fault [25]. PALSAR operated with full polarization from single HH (Horizontal send/receive) to VV (Vertical send/receive) and dual $\mathrm{HH}+\mathrm{HV}$ or VV $+\mathrm{VH}$ and quad-pol, $8^{\circ}$ to $60^{\circ}$ offnadir incident angle, $28 \mathrm{MHz}$ and $14 \mathrm{MHz}$ bandwidths in modes of Fine Beam Single (FBS, $28 \mathrm{MHz}, \mathrm{HH}$ ), Fine Beam Dual (FBD, 14 MHz, HH-VV), Polarimetry (POL, 14 MHz, quad-pol), Direct Downlink (DD, 14 MHz, $\mathrm{HH} / \mathrm{HV}$ or VV/VH) and ScanSAR (14 MHz, HH) [21]-[24]. The fixed-position right-looking 3-by-9 m antenna array uses a L-band center wavelength is $236 \mathrm{~mm}$ at a frequency of $1270 \mathrm{MHz}$. Ground resolution is nominal 10 $\mathrm{m}$ in range and azimuth in FBS mode and nominal $20 \mathrm{~m}$ in range and $10 \mathrm{~m}$ in azimuth in FBD mode with swaths widths at $70 \mathrm{~km}$ (34.3 $3^{\circ}$ off-nadir angle) [24]. Radiometric accuracies of $1 \mathrm{~dB}$ per scene and $1.5 \mathrm{~dB}$ per orbit were achieved. The ALOS attitude, orbit and control system included a star-camera, dual-frequency GPS unit and a square corner retro-reflector that allowed for spacecraft position accuracy of $1 \mathrm{~m}$ and ground-track geolocation accuracy of 3 to $7.5 \mathrm{~m}$ [21]-[24]. Therefore, the quality (e.g. coherence/incoherence) of interferometric pairs varies from pair-to-pair.

Using multiple survey-grade GPS stations, precisely located corner reflectors and groups of two-pass InSAR interferograms the absolute accuracy [total error] of PALSAR Line-Of-Sight (LOS) difference (i.e. change) is $74 \mathrm{~mm}$ [25]. Variation of tropospheric water vapor, pressure and temperature affecting the optical path during multi-pass SAR acquisitions can contribute about $20 \mathrm{~mm}$ to the total LOS difference error [26]. These affects are independent to those of the upper atmosphere such as Faraday rotation and Total Electron Content that also affect the optical path and contribute to the total error. A contribution of about $3 \mathrm{~mm}$ per $10 \mathrm{~m}$ of topographic error (vertical) to the total LOS difference error can be made during InSAR processing, stressing the need for a high-accuracy Digital Elevation Model (DEM) to remove the topographic phase during InSAR processing [25].

In our investigation we use pairs of PALSAR FBD and FBS granules in ascending and descending paths for Interferometric SAR (InSAR) processing, Figure 2. Covering the Anaktuvuk wildfire scar area we use four FBS granules and covering the Barrow area we use three FBD and one FBS granules (Table 3). Our InSAR processor converted a matching FBD granule to an FBS granule to form an InSAR-pair, giving two consecutive interferograms. Our FBD and FBS granules have off-nadir angles of 34.3, indicating the critical perpendicular baselines are $6.5 \mathrm{~km}$ for FBD and $13.1 \mathrm{~km}$ for FBS. All of our FBD and FBS granules have perpendicular baselines far below the critical values.

The InSAR Processor we use is the GMTSAR, C-code routines that incorporates the SNAPHU unwrapper and the Generic Mapping Tools (GMT) C-code routines and scripts [27]-[30]. GMTSAR, SNAPHU and GMT are open-source community projects and maintained regularly since 1991 (GMT), 2010 (GMTSAR) and 2002 (SNAPHU). The University of Hawaii Mānoa, Honolulu, University of California San Diego and Stanford University hold the open-source copyrights, respectively. Parts of the SNAPHU code derive from the CS2 minimum cost solver (A.V. Goldberg and B. Cherkassky) is governed with evaluation-permission to use by IG Systems, Inc., 1995 [28]. The National Science Foundation Directorate for Geosciences has been an active supporter of the development, distribution, documentation and maintenance of GMT since 1993 [30].

In our InSAR processing on the permafrost terrains of the north slope of Alaska we use two DEMs to explore the affects to interferograms from topographic phase. Our test show that the Altimetry Corrected Elevation

${ }^{4}$ https://directory.eoportal.org/web/eoportal/satellite-missions/a/alos. 
Table 3. ALOS PALSAR interferometric-pair granules and properties.

\begin{tabular}{|c|c|c|c|c|c|c|c|c|}
\hline $\begin{array}{l}\text { Granule } \\
\text { Barrow }\end{array}$ & Date & $\begin{array}{l}\| \mathrm{B} \\
(\mathrm{m})\end{array}$ & $\frac{1}{(\mathrm{~m})} \mathrm{B}$ & $\begin{array}{c}\text { TS } \\
\text { (days) }\end{array}$ & OMode & $\begin{array}{l}\text { FR } \\
\text { (deg.) }\end{array}$ & AMode & $\begin{array}{l}\text { ONA } \\
\text { (deg.) }\end{array}$ \\
\hline ALPSRP081662180 & 2007-08-06 & $\sim$ & $\sim$ & $\sim$ & $\mathrm{D}$ & 3.1 & FBS & 34.3 \\
\hline ALPSRP095082180 & 2007-11-06 & 321 & 844 & 92 & $\mathrm{D}$ & 2.0 & FBS(FBD) & 34.3 \\
\hline ALPSRP095082180 & 2007-11-06 & $\sim$ & $\sim$ & $\sim$ & $\mathrm{D}$ & 2.0 & FBD & 34.3 \\
\hline ALPSRP101792180 & $2007-12-22$ & 569 & 501 & 46 & $\mathrm{D}$ & 1.0 & FBD & 34.3 \\
\hline \multicolumn{9}{|l|}{ Anaktuvuk } \\
\hline ALPSRP019001380 & 2006-06-03 & $\sim$ & $\sim$ & $\sim$ & A & 3.8 & FBS & 34.3 \\
\hline ALPSRP233721380 & 2010-06-14 & 4893 & 4710 & 1771 & A & 3.3 & FBS & 34.3 \\
\hline ALPSRP019001390 & 2006-06-03 & $\sim$ & $\sim$ & $\sim$ & A & 3.8 & FBS & 34.3 \\
\hline ALPSRP233721390 & 2010-06-14 & 4904 & 4715 & 1472 & A & 3.3 & FBS & 34.3 \\
\hline
\end{tabular}

|| B = Parallel Baseline; $\perp$ B = Perpendicular Baseline; TS = Time Separation in days; OMode= Orbit Mode (A = Ascending, D = Descending); FR = Faraday Rotation; AMode = Acquisition Mode; ONA = Off-Nadir Angle.

Global DEM version 2 (ACE2) performs best on the very low relief of the outer coastal plain and the ASTER Global DEM version 2 (AGD2) performs best on the on the higher relief of the coastal foothills and the Brooks Range [31]-[33]. This performance-quality difference is an expression of the different production standards and techniques of the DEMs, e.g. ERS 1/2 and Envisat nadir-microwave altimetry applied to the GTOPO30 (latitudes beyond $60^{\circ} \mathrm{N}$-to- $60^{\circ} \mathrm{S}$ ) to produce ACE2 and nadir-off angle stereogrammetry to produce AGD2.

\section{Results}

Our results of this research investigation of land-surface changes GLAS elevation differences and PALSAR LOS changes, in- and out-side of the Anaktuvuk wildfire scar are summarized in Figure 3 and Figure 4 and Table 4 and Table 5. Figure 3 illustrates the PALSAR LOS change maps covering the upper and lower half of the wildfire scar and the GLAS elevation difference (rendered as LOS changes). Annotated are pingos (ice-cored mounds) whose stable positions we use as natural benchmarks. Of the five pingos (about $100 \mathrm{~m}$ diameters) three have coinciding LOS changes and two others have only incoherent pixels. Black-bars on the LOS change scales represent the absolute LOS error of $74 \mathrm{~mm}$ [25].

The overpass periods for ALOS PALSAR and ICESat GLAS are given in Figure 3. Two of the GLAS exact-repeat difference profiles are from acquisitions before and two overlap the ALOS PALSAR acquisitions. All ICESat GLAS acquisitions occurred before the Anaktuvuk wildfire.

The ICESat GLAS elevation differences (recast as LOS change) show greater magnitudes than the ALOS PALSAR LOS changes, Figure 3. In the given scales the ICESat GLAS elevation changes cluster beyond the red-bound of LOS range decrease (rising scatters) and beyond the blue-bound of LOS range increase (lowering scatters), assuming a stable orbit. ICESat GLAS acquisitions during and after the wildfire were not successful due to blockage by fire smoke and cloud cover.

Outside the wildfire scar ALOS PALSAR shows clusters of LOS range changes, decrease and increase, that are above error, Figure 3. These clusters are notable in size at the northern scar extent, the northwest and southwest scar extent and in a region east of the scar extent by several kilometers in both granule-pair LOS change maps. The rivers marking the east and west physical bounds of the wildfire scar have LOS changes (decrease and increase) above error. Within the wildfire scar very few pixels have coherence and measurable LOS range changes.

Figure 4 illustrates ICESat GLAS elevation profiles, elevation difference profiles (upper half) and ICESat GLAS footprint centroid geolocation coordinates to extract ALOS PALSAR LOS changes (lower half) for comparison. The top-most panels are elevation profiles for the given acquisition date of one of the exact-repeat pairs. Below the top-most panels are the elevation difference profiles, having a low-pass filter applied for outlier removal. The red-dash lines represent snow thickness difference by way of the ICESat overpass dates from snow thickness measurements at Franklin Bluffs permafrost borehole station site (FB) east of the wildfire scar and 


\section{ALOS $\Delta t: 20060603$ to 20100614}

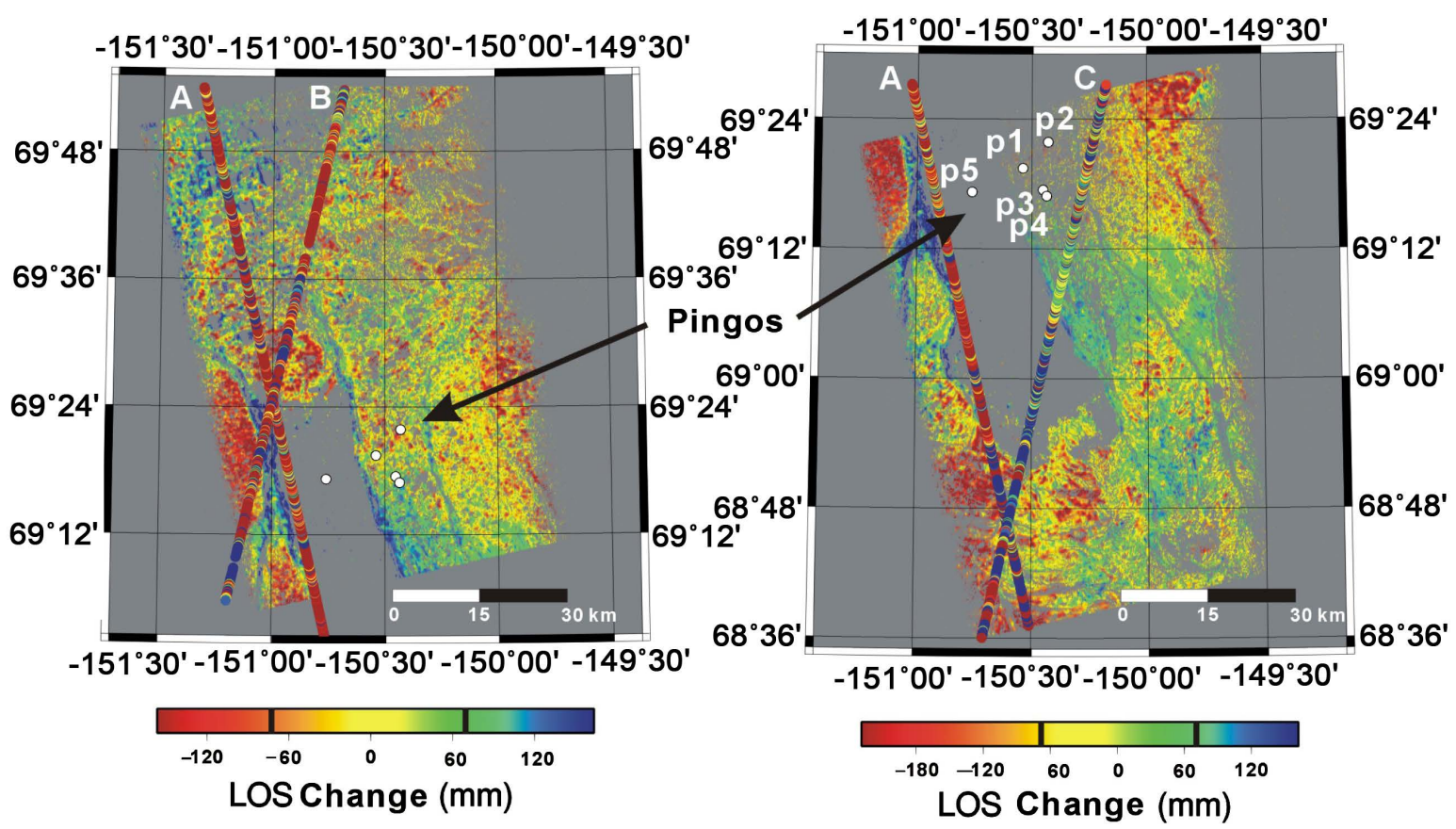

\section{A ICESat $\Delta$ t: 20031027 to 20060305 \\ A ICESat $\Delta t$ : 20031027 to 20060305 \\ B ICESat $\Delta$ t: 20061115 to 20070402 \\ C ICESat $\Delta$ t: 20031114 to 20061123}

Figure 3. ALOS PALSAR Line-Of-Sight (LOS) change maps covering the Anaktovuk wildfire scar, and ICESat GLAS elevation change profiles for comparison. Locations of pingos as numbered in Table 5 are shown. Black-bars on the LOS change map scales show the range of absolute error $(74 \mathrm{~mm})$ [25]. Dates are giver for the ALOS repeat-overpasses and ICESat exact-repeat overpasses.

Table 4. Comparison of snow thickness measurements and differences at Franklin Bluffs (FBW) and Umiat (U24) sites during ICESat and ALOS overpasses with GLAS average elevation difference.

\begin{tabular}{|c|c|c|c|c|c|}
\hline ICESat Dates & $\begin{array}{c}\text { FBW } \\
(\mathrm{m})\end{array}$ & $\begin{array}{l}\mathrm{U} 24 \\
\text { (m) }\end{array}$ & $\begin{array}{c}\text { FBW } \\
\text { (m) }\end{array}$ & $\begin{array}{l}\text { U24 } \\
\text { (m) }\end{array}$ & $\begin{array}{c}\text { GLAS } \\
\text { (m) }\end{array}$ \\
\hline 10/27/2003 & 0.10 & 0.30 & & & \\
\hline 03/05/2006 & 0.46 & 0.41 & 0.36 & 0.11 & 0.28 \\
\hline $11 / 15 / 2006$ & 1.49 & 0.10 & & & \\
\hline 04/02/2007 & 1.49 & 0.26 & 0 & 0.16 & 0.09 \\
\hline $11 / 14 / 2003$ & 0.09 & 0.37 & & & \\
\hline $11 / 23 / 2006$ & 1.49 & 0.16 & 1.40 & -0.19 & -0.08 \\
\hline \multicolumn{6}{|l|}{ ALOS Dates } \\
\hline 06/03/2006 & 0 & 0.04 & & & \\
\hline 06/14/2010 & 0.02 & 0.06 & 0.02 & 0.02 & \\
\hline
\end{tabular}

Difference in snow thickness is by later-date minus former-date.FBW (UAF Geophysical Permafrost Laboratory/GTN-P) and U24 (USGS DOI/GTNP)

from Umiat USGS site (U24) west of the wildfire scar (see Figure 1 for site locations and Table 4 for values). The comparison confirms that ICESat GLAS elevation differences are in response to snow thickness differences (i.e. thickness change, on average) at the pair-wise overpass times (Figure 4 and Table 4). 

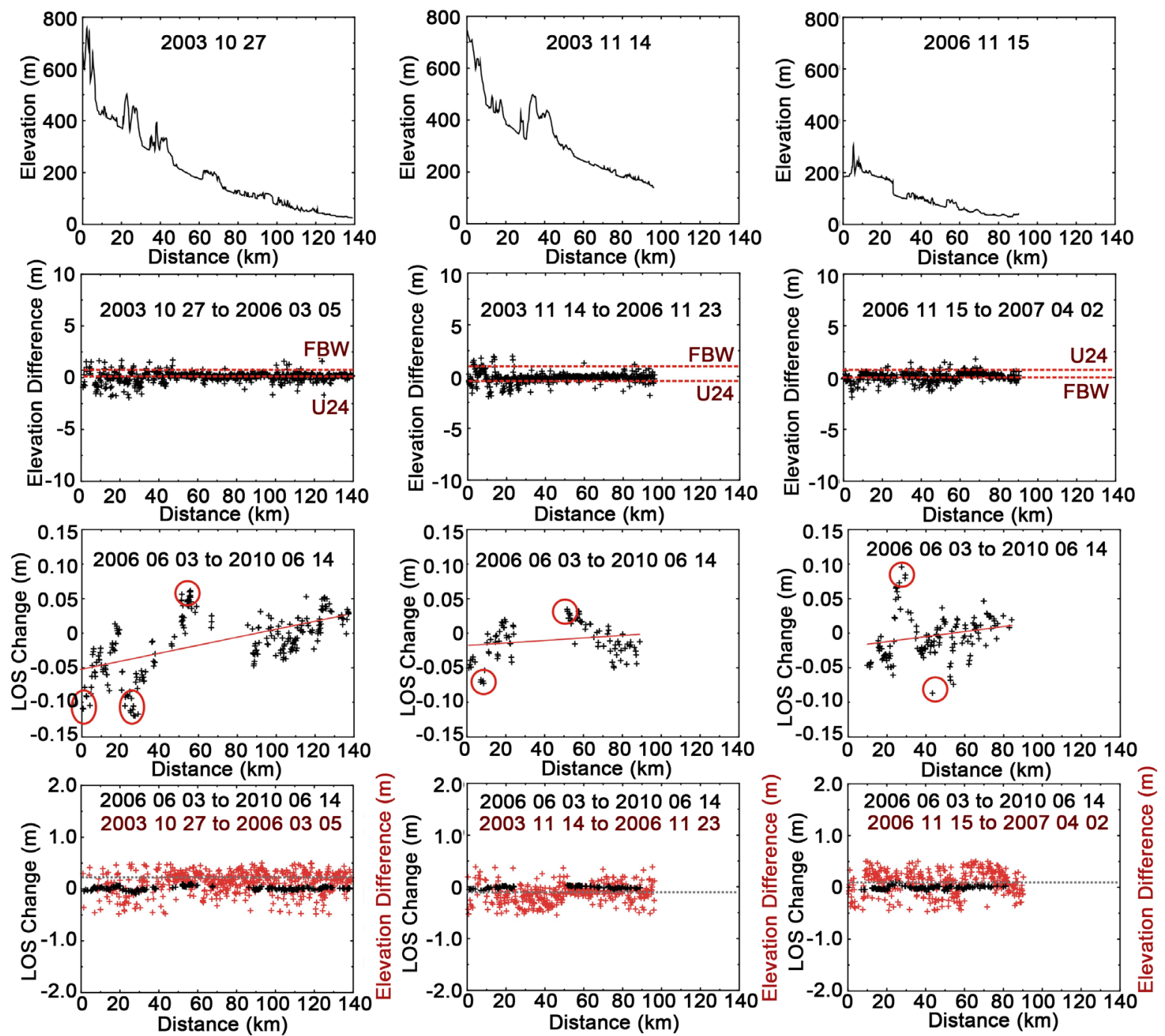

Figure 4. Analysis of co-located ICESat GLAS elevation profiles, elevation difference (i.e. changes) profiles, ALOS PALSAR LOS change profiles and slope-corrected (regression de-trended) PALSAR LOS change profiles compared with GLAS elevation difference profiles. Red-dash lines (next to top-most profiles) correspond to snow thickness change from Franklin Bluffs (FBW) and Umiat (U24) as in Table 4. Red-circles (above lower most profiles) identify LOS changes above total error corresponding to riverbank deposition (negative) and erosion (positive). Black-dash lines (lower most profiles) correspond to average GLAS elevation changes.

Table 5. PALSAR LOS bias at pingos.

\begin{tabular}{cccc}
\hline Pingo & Average $(\mathrm{m})$ & Standard Dev. $(\mathrm{m})$ & Number \\
\hline p1_u & -0.006 & 0.002 & 14 \\
p3_u & 0.027 & 0.002 & 20 \\
p4_u & 0.028 & 0.002 & 11 \\
p1_l & -0.031 & 0.001 & 2 \\
p3_l & 0.008 & 0.000 & 3 \\
p4_l & 0.012 & NA & 1 \\
p1_ul & -0.009 & 0.009 & 23 \\
p3_ul & 0.024 & 0.007 & 12 \\
p4_ul & 0.027 & 0.005 & 51
\end{tabular}


ALOS PALSAR LOS changes extracted by way of ICESat GLAS footprint centroid coordinates allow for close inspection and detection of gradients (Figure 4 lower half panels). The plots with circles and least squares regression lines show the LOS range changes that are greater than the total error. These LOS changes correspond to the locations where riverbanks occur. This indicates that LOS decrease (i.e. rising scatters) corresponds to locations of sediment deposition and LOS increase (i.e. lowering scatters) corresponds to locations of sediment erosion along riverbanks. The least squares regression lines indicate gradients that could correspond to re sidual topography phase or atmospheric phase, possibly both, not accounted for in the InSAR processing. In the bottom most panels we de-trend the PALSAR LOS changes by the least squares regressions and compare again to the GLAS elevation differences (low pass filtered). The gray dashed lines correspond to GLAS elevation difference averages (Table 4). We note that LOS changes at the sites of pingos (Table 5) show bias of $0.02 \pm 0.02$ $\mathrm{m}$ within the total error. This indicates the PALSAR LOS changes, other than those on riverbanks and region clusters as previously noted, do not correspond to surface scatters; rather these LOS changes correspond to volume scatters (by way of the short tussock vegetation and shallow sub-ground within the active-layer, i.e. seasonally unfrozen soil). Therefore volume scattering acts to increase the path length of the radar signal and dissipates the radar energy and power of the backscatter signal response.

\section{Discussion}

The Anaktuvuk wildfire scar and surrounding region shown in Figure 1 and Figure 4 resides within the Colville Basin, a foreland fold-fault structure fronting the folded thrust sheets of the Endicott Mountains Allochathon of the Brooks Range [34]. Near Umiat there are three at depth gas accumulations, one oil accumulation (test drilled) and one active gas well. The region between Franklin Bluffs to Umiat has 13 abandoned wells [34]. The surficial geology of this region consists of undifferentiated Holocene and Pleistocene fine-grained, organic-rich silt, loess, and local colluvium and fine-grained alluvial sand and silt in areas adjacent to upland slopes and river courses consisting of alluvial-glacial sand, silt and gravel, landslide (from active-layer slides and regressive thaw slumps) and reworked sand-silt deposits [34] [35]. Along the course of the Anaktuvuk River that forms the west-side boundary of the Anaktuvuk wildfire scar occur outcrops (bluffs) of the Cretaceous-Tertiary Prince Creek Formation (upper part dominated by fine-grained sandstone with interlayered silt-carbonaceous shale, thin coal beds and basal conglomeratic sandstone) [35] [36]. This formation outcrops as ridges adjacent to the north side of the scar [35] [36].

The active-layer thickness on the terrains of the North Slope is typically about $0.5 \mathrm{~m}$ with small centimeter-scale variations near the coastal lowlands and through the foothills terrain (FB and U24 sites) [37]. During early-June the shallow $0.1 \mathrm{~m}$ depth soil moisture-water volume fraction (wvf) changes the most on a per day basis because of rapid thawing. Saturation occurs at $0.45 \mathrm{wvf}$ at FB and $0.52 \mathrm{wvf}$ at U24 near mid-June of any year [38]. Thus the near-surface soil moisture change at both sites is near 0 wvf during the ALOS June 2006 and 2010 overpass interval.

Figure 5 illustrates the coherence maps of the PALSAR granule-pairs. InSAR phase coherence, $|\gamma|$ a function of value zero (no coherence) to 1 (maximum coherence) is defined by the magnitude of the pixel-level crosscorrelation of two co-registered complex images [39]. The physical nature of phase coherence derives from thermal, spatial and temporal coherence functions,

$$
|\gamma|=\left|\gamma_{\text {thermal }}\right| \cdot\left|\gamma_{\text {spatial }}\right| \cdot\left|\gamma_{\text {temporal }}\right|[40]
$$

Thermal and temporal coherence derive from the characteristics of the ALOS orbit and PALSAR such that $\left|\gamma_{\text {thermal }}\right| \sim 1$ and $\left|\gamma_{\text {temporal }}\right| \sim 1$ [39]. The physical nature of spatial coherence derives from surface and volume scatters such that.

$$
\left|\gamma_{\text {spatial }}\right|=\left|\gamma_{\text {surface }}\right| \cdot\left|\gamma_{\text {volume }}\right|[41]
$$

This we can decompose into two relationships:

$$
\begin{aligned}
& \left|\gamma_{\text {surface }}\right|=\left|\gamma_{\text {spatial }}\right| /\left|\gamma_{\text {volume }}\right| \\
& \left|\gamma_{\text {volume }}\right|=\left|\gamma_{\text {spatial }}\right| /\left|\gamma_{\text {surface }}\right|
\end{aligned}
$$

These relationships allow for the interpretation of the mutual contribution of surface scatters and volume 

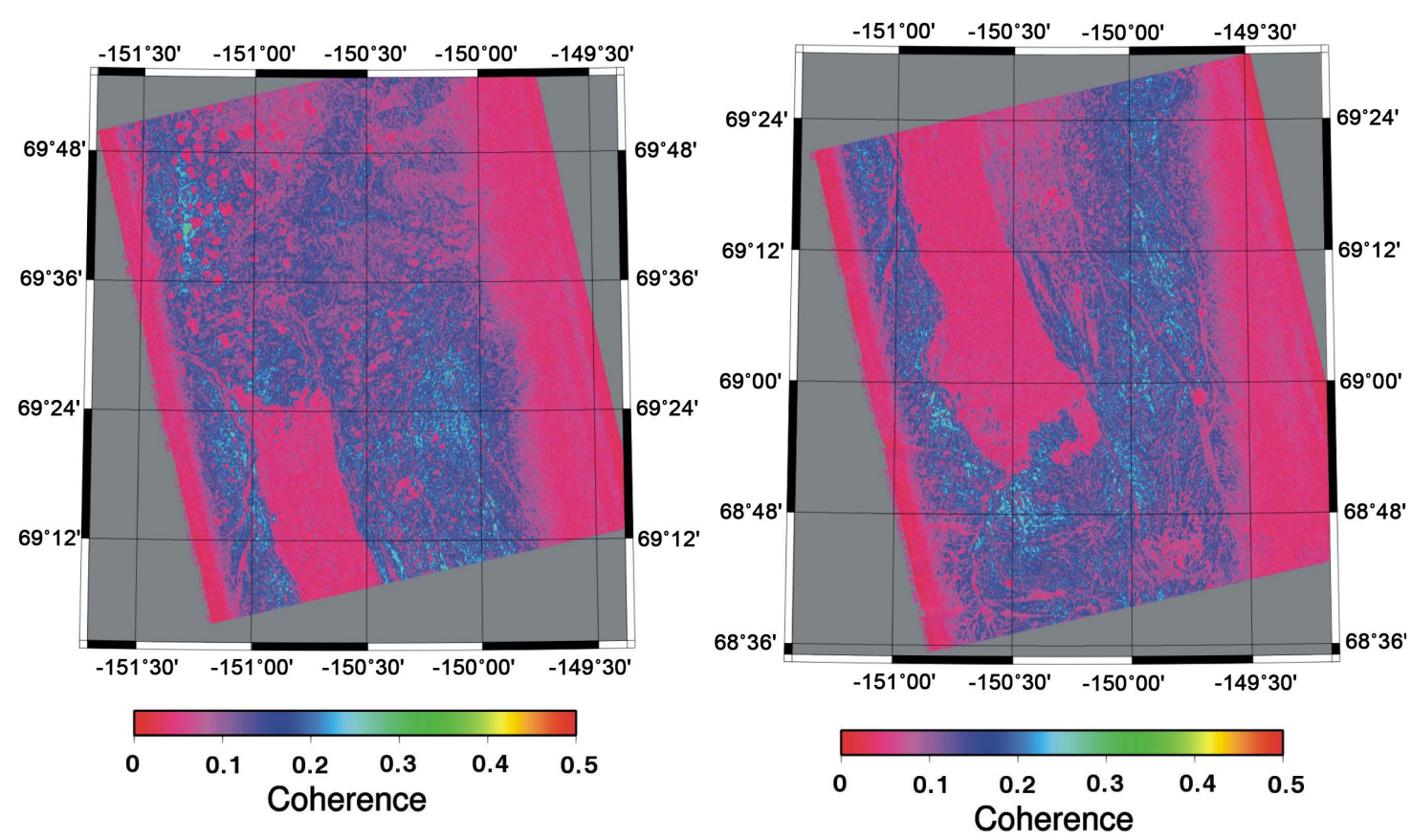

Figure 5. ALOS PALSAR InSAR coherence maps. Relatively higher coherence (surface scatters) occurs on rock outcrops (ridges and river bluffs) and low coherence (volume scatters) occurs on tundra vegetation active-layer.

scatters to the magnitude of phase coherence (1). As the thickness of the volume (and volume parts, one from tussock and one from shallow soil) increase, the corresponding coherence decreases (mostly volume scatters, i.e. $\left|\gamma_{\text {surface }}\right|$ is minimized) and as the thickness of the volume (and parts) decrease, the corresponding coherence increases (mostly surface scatters, i.e. $\left|\gamma_{\text {surface }}\right|$ is maximized). This allows for a rational of why the PALSAR LOS changes, with a few exceptions at river channels/banks and rock outcrops are near zero (mostly volume scatter sources) while the GLAS elevation changes are of much greater magnitude (surface scatter sources). This is a way of saying that the function of volume scattering is to increase the radar path length and dissipate energy, thus diminishing the power of the radar return echo.

In the results and as illustrated in Figure 4, we de-trended the profiles of PALSAR LOS changes. We noted slopes as detected could be of a residual topography phase or perhaps an atmosphere phase not accounted for in the InSAR processing. We will now use 94- and 47-day separation InSAR granule-pairs on the Barrow peninsula of Alaska, Figure 2, to illustrate the contribution of atmospheric phase, i.e. tropospheric phase, to the interferograms and resolving this contribution using NOAA National Centers for Environmental Prediction (NCEP) reanalysis troposphere pressure data, Figure 6 and Figure 7.

Figure 6 shows the Barrow region PALSAR 47-day granule-pair LOS change map with an ICESat GLAS elevation change (rendered as LOS changes). We extract the PALSAR LOS changes coincident with the ICESat GLAS exact-repeat footprint centroid coordinates for comparison. GLAS elevations indicate low tide on the Meade River ice-covered channels connecting to Admiralty Bay (30 km mark) and Chukchi near shore sea ice (90 km). We validated the low-tide condition using NOAA Barrow-Offshore station (\#9494935) verified data for 12 December 2008. Tide variation measurements by ICESat GLAS have been analyzed and reported for the ice-covered channels of the Lena Delta and near-shore ice-cover of the Laptev Sea [20]. The LOS changes indicate a strong gradient (i.e. ramp) oriented to the northeast Beaufort Sea coast. The LOS changes are positive, indicating the distance from ALOS to the ground is increasing. If the ALOS orbit is not contributing to the LOS changes, then we can interpret that the surface of the Barrow region is sinking toward the Chukchi Sea coast. This is physically unreasonable. Unwrapped phase and LOS change ramps have been derived before using ERS Tandem Mission SAR data for InSAR processing of digital elevation models [16]. The gradient does not correspond to topography, i.e. topographic phase (it has been removed) or any other surface scatter source and is not a processing artifact. It does not correlate to the ICESat GLAS elevation changes. However, it does have physical source. This we will explain using Figure 7. 

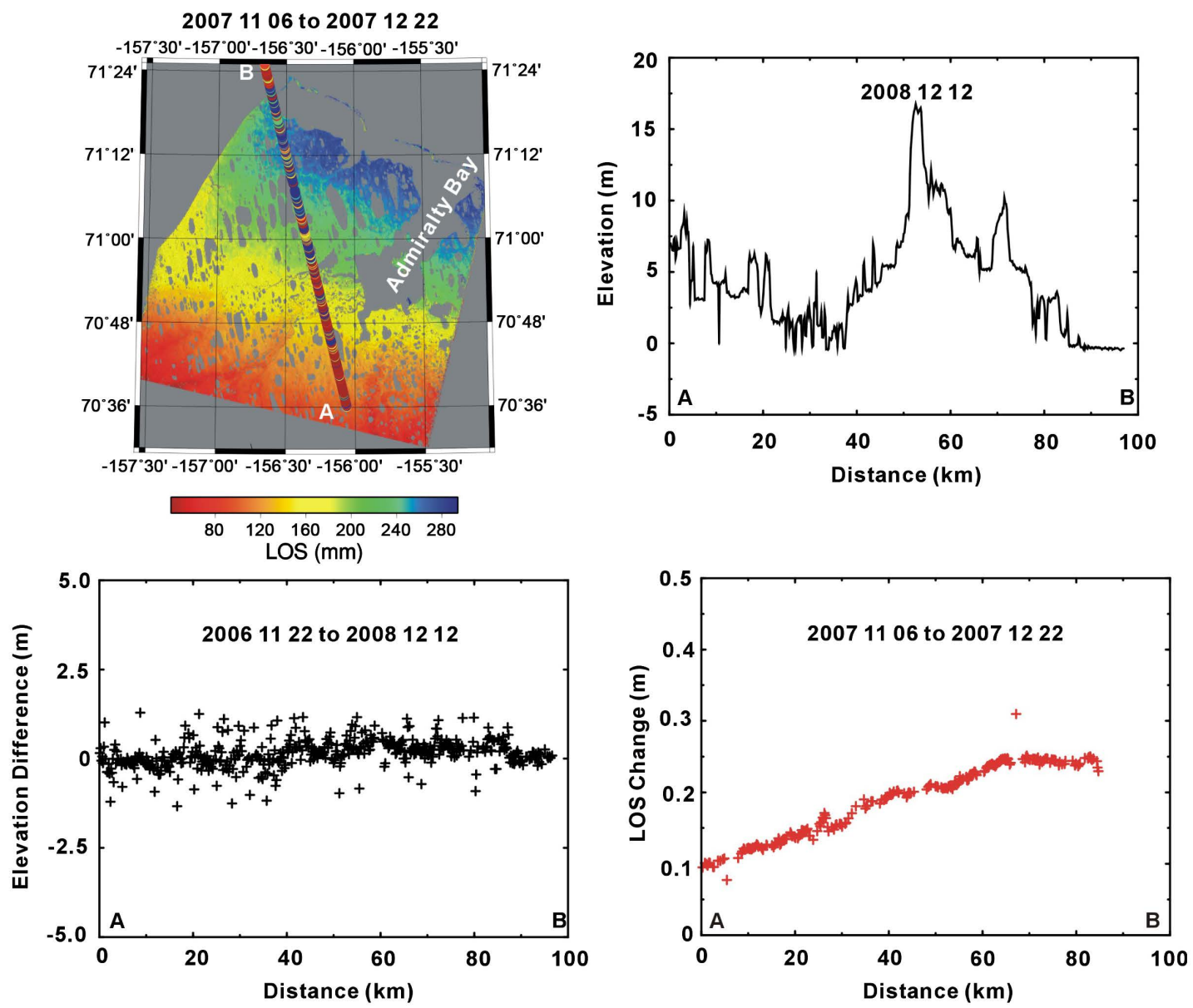

Figure 6. Barrow region used for analysis of ICESat GLAS elevation and elevation change from exact-repeat profiles for presence of troposphere phase effect on ALOS PALSAR LOS change map. The PALSAR LOS change map with GLAS elevation change profile (upper left). GLAS elevation profile for 12 December 2008 is shown (upper right). GLAS elevation difference (i.e. change) profile from exact-repeat profiles at dates is shown (lower left). PALSAR LOS change (meter scale) co-located on the GLAS elevation difference profile is shown (lower right).

The top of Figure 7 shows the PALSAR granule-pairs LOS change maps at the ALOS overpass times rendering 94-day and 47-day repeat intervals. As before, the topographic phase has been removed. Evident in the LOS change maps are gradients whose orientations are correlated to the overpass interval. The 94-day LOS change map shows the gradient oriented relative to the northwest, Chukchi Sea coast. The 47-day LOS change map shows the gradient oriented northeast to the Beaufort Sea coast. We use NCEP reanalysis of the tropopause pressure field (mb) to compute the anomaly in tropopause pressure (i.e. pressure change) at the dates of the PALSAR granule-pairs. This shows that the LOS gradients are mostly an expression of tropopause pressure changes (gradients in the LOS change maps). Troposphere pressure field, atmospheric moisture and wind fields and their seasonal variations, e.g. non-stationarity, are an expression of the Beaufort Gyre, a well-known atmosphere-ocean pattern of the Arctic Ocean [42]. Troposphere pressure, water vapor and temperature variations serve to alter the optical path of the radar [5] [16]. In regard to the anomalous slopes (i.e. gradients), Figure 4, in the PALSAR LOS change maps covering the region of the Anaktuvuk wildfire scar, are also an expression of troposphere pressure variations that altered the optic path of the radar during the during the ALOS overpass times, Figure 3. Therefore our de-trending procedure served to remove the effects of troposphere phase as well as any residual topographic phase from the interferograms and LOS change maps, hence leaving the ground volume scatters (subsurface and vegetation) present.

Our result shows that coherent short-period tropospheric phase will impact interferogram stacking. If tropospheric phase is not removed from each granule-pair interferogram in the stack, then the end product is simply 


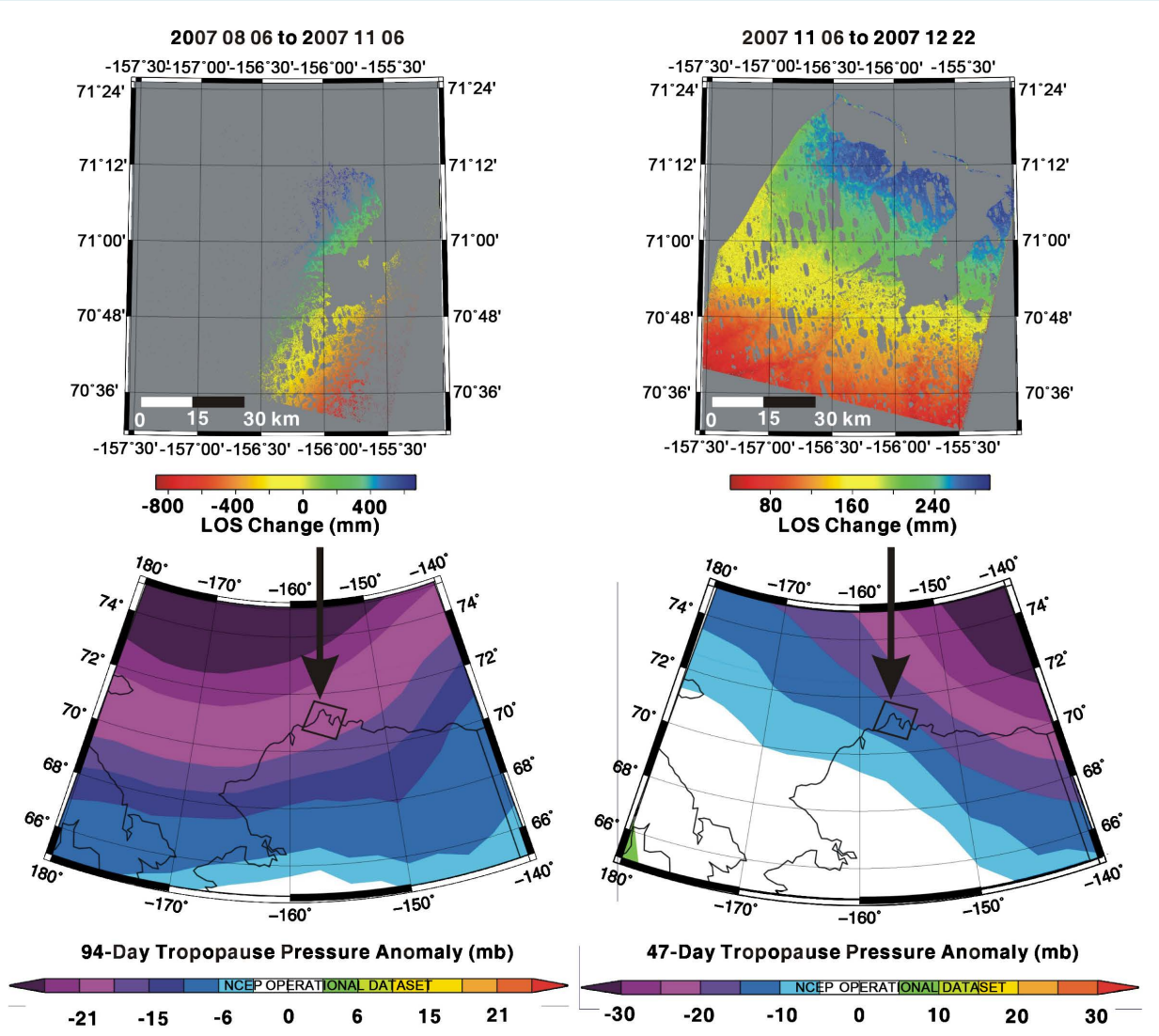

Figure 7. ALOS PALSAR LOS change maps (upper left and right) on the Barrow region and NCEP reanalysis tropopause anomaly maps (lower left and right) at the dates of ALOS repeat-overpasses. Left maps correspond to the 94-day ALOS repeat-overpass and the right maps correspond to the 47-day ALOS repeat-overpass. The PALSAR LOS gradients correspond to the NCEP tropopause anomaly gradients (i.e. a strong source of troposphere phase affecting the InSAR interferograms and LOS change maps). The shift of the tropopause anomaly is caused by the seasonal non-stationarity of the Beaufort Sea Gyre.

the sum of different tropospheric phases in time and not surface deformation phase. This is a serious limitation to the idea of persistent scatters relative to surface deformation phase in the presence of unaccounted for tropospheric phase. Prior investigations that failed to realize this and in addition to not account for influence of river dynamics, such as spring flooding deposition and erosion, regional geology, analysis of error and establishment of a stable vertical reference leaves their speculations unfounded [43]-[45].

A final consideration concerns the error budget and how it is determined. To date, all satellite-based SAR operations and InSAR rely on methods and techniques for error analysis of only surface scatters and not volume scatter [25] [26]. At present the error contribution from volume scatters is unknown. This should be a major research priority for the satellite-SAR InSAR community to determine the contribution to the error budget from volume scatter sources.

\section{Conclusion}

In this paper, we summarize our research investigation of the ICESat GLAS elevation changes and the ALOS PALSAR LOS changes on the continuous permafrost zone of the North Slope, Alaska. Using the ICESat GLAS exact-repeat profiles in the analysis of ALOS PALSAR LOS changes, we find evidence of volume scattering over much of the tundra vegetation covered active-layer and surface scattering from river channel/banks (both deposition and erosion), from rock outcropping bluffs along river courses and ridges. Pingos, ice-cored mounds common to permafrost terrains can be used as natural benchmarks for assessment of re-peat pass satellite-based InSAR LOS changes in a stable vertical reference frame. For successful InSAR processing, topographic and tropospheric phase must be removed. In particular, tropospheric phase is not negligible over the North Slope, Alaska, and other lowland coastal regions where strong atmospheric-ocean circulations and gyres occur. 


\section{Acknowledgements}

We thank NASA and NSIDC for providing the ICESat mission GLAS datasets and JAXA and the Alaska Satellite Facility, University of Alaska Fairbanks (UAF), for providing the ALOS mission PALSAR datasets. We thank the UAF Geophysical Institute (GI) Arctic Region Supercomputing Center for use of ENVI/IDL programming package and computing facilities used over the course of this investigation. GMTSAR and the Generic Mapping Tools were used in this research. We thank NOAA National Centers for Environmental Prediction for atmosphere data and NOAA Center for Operational Oceanographic Products and Services for offshore tide data at Barrow, Alaska. Funding was provided by Vladimir E. Romanovsky through grants from DOE NextGeneration Ecosystem Experiment, NASA, NSF Alaska EPSCoR and Arctic Observing Network Thermal State of Permafrost (TSP), State of Alaska and the USGS Climate Science Center, and for Franklin Bluffs data: GI Permafrost Laboratory (2015) NSF TSP [FB1 \& FBW]: http://permafrost.gi.alaska.edu. We thank Frank E. Urban and Gary D. Clow, USGS GTN-P for data from Umiat (http://pubs.usgs.gov/ds/812/Umiat/Umiat.html).

\section{References}

[1] Farr, T.G., Rosen, P.A., Caro, E., Crippen, R., Duren, R., Hensley, S., Kobrick, M., Paller, M., Rodriguez, E., Roth, L., Seal, D., Shaffer, S., Shimada, J., Umland, J., Werner, M., Oskin, M., Burbank, D. and Alsdorf, D. (2007) The Shuttle Radar Topography Mission. Reviews of Geophysics, 45, 1944-9208. http://dx.doi.org/10.1029/2005RG000183

[2] Alsdorf, D.E., Smith, L.C. and Melack, J.M. (2001) Amazon Floodplain Water Level Changes Measured with Interferometric SIR-C Radar. IEEE Transactions on Geoscience and Remote Sensing, 39, 423-431. http://dx.doi.org/10.1109/36.905250

[3] Treuhaft, R.N., Madsen, S.N., Moghaddam, M. and van Zyl, J.J. (1996) Vegetation Characteristics and Underlying Topography from Interferometric Radar. Radio Science, 31, 1449-1485. http://dx.doi.org/10.1029/96RS01763

[4] Riedel, B. and Walther, A. (2008) InSAR Processing for the Recognition of Landslides. Advances in Geoscience, 14, 189-194. http://dx.doi.org/10.3390/rs5062590

[5] Hanssen, R.F., Weckwerth, T.M, Zebker, H.A. and Klees, R. (1999) High-Resolution Water Vapor Mapping from Interferometric Radar Measurements. Science, 283, 1297-1299. http://dx.doi.org/10.1126/science.283.5406.1297

[6] Helz, R.L. (2005) Monitoring Ground Deformation from Space. US Geological Survey, Fact Sheet 2005-3025, Department of Interior, Washington DC.

[7] Bawden, G.W., Sneed, M., Stork, S.V. and Galloway, D.L. (2003) Measuring Human-Induced Land Subsidence from Space. US Geological Survey, Fact Sheet 069-003, Department of Interior, Washington DC.

[8] Joughin, I., Smith, B.E. and Abdalati, W. (2010) Glaciological Advances Made with Interferometric Synthetic Aperture Radar. Journal of Glaciology, 56, 1026-1042. http://dx.doi.org/10.3189/002214311796406158

[9] Ferretti, A., Monti-Guarnieri, A., Prati, C., Rocca, F. and Massonnet, D. (2007) InSAR Principles: Guidelines for SAR Interferometry Processing and Interpretation. European Space Agency Publications ESTEC, Noordwijk.

[10] Constantinova, G.S. (1978) Permafrost Landscape, 133-135 in Permafrost: Second International Conference, 13-28 July 1973, National Academy of Sciences, Washington DC.

[11] Scheffers, A.M., May, S.M. and Kelletat, D.H. (2015) Chapter 13: Frost and Permafrost as Morphological Agents (Or the Perglacial Domain). In: Scheffers, A.M., May, S.M. and Kelletat, D.H., Eds., Landforms of the World with Google Earth: Understanding Our Environment, Springer, Dordrecht, 347-374.

[12] Slaymaker, O. and Kelly, R.E.J. (2007) Chapter 2: Traditional In-Situ Approaches to the Monitoring of Cryosphere Change. In: Slaymaker, O. and Kelly, R.E.J., Eds., The Cryosphere, Environmental Systems and Global Change Series, Blackwell Publishing, Malden, 49.

[13] National Research Council USA (2014) Opportunities to Use Remote Sensing in Understanding Permafrost and Related Ecological Characteristics: Report of a Workshop. The National Academies Press, Washington DC.

[14] Zwally, H.J., Schutz, B., Abdalati, W., Abshire, J., Bentley, C., Brenner, A., Bufton, J., Dezio, J., Hancock, D., Harding, D., Herring, T., Minster, B., Quinn, K., Palm, S., Spinhirne, J. and Thomas, R. (2002) ICESat's Laser Measurements of Polar Ice, Atmosphere, Ocean, and Land. Journal of Geodynamics, 34, 405-445. http://dx.doi.org/10.1016/S0264-3707(02)00042-X

[15] Schutz, B.E., Zwally, H.J., Schuman, C.A., Hancock, D. and DiMarzio, P.J. (2005) Overview of the ICESat Mission. Geophysical Research Letters, 32, Article ID: L21S01. http://dx.doi.org/10.1029/2005gl024009

[16] Atwood, D.K., Guritz, R.M., Muskett, R.R., Lingle, C.S., Sauber, J.M. and Freymueller, J.T. (2007) DEM Control in Arctic Alaska with ICES at Laser Altimetry. IEEE Transactions on Geoscience and Remote Sensing, 45, 3710-3720. http://dx.doi.org/10.1109/TGRS.2007.904335 
[17] Muskett, R.R., Lingle, C.S., Sauber, J.M., Rabus, B.T. and Tangborn, W.V. (2008) Acceleration of Surface Lowering on the Tidewater Glaciers of Icy Bay, Alaska, USA, from InSAR DEMs and ICESat Altimetry. Earth and Planetary Science Letters, 265, 345-359. http://dx.doi.org/10.1016/j.epsl.2007.10.012

[18] Muskett, R.R., Lingle, C.S., Sauber, J.M., Post, A.S., Tangborn, W.V. and Rabus, B.T. (2008) Surging, Accelerating Surface Lowering and Volume Reduction of the Malaspina Glacier System, Alaska, USA, and Yukon, Canada, from 1972 to 2006. Journal of Glaciology, 54, 788-800. http://dx.doi.org/10.3189/002214308787779915

[19] Muskett, R.R., Lingle, C.S., Sauber, J.M., Post, A.S., Tangborn, W.V., Rabus, B.T. and Echelmeyer, K.A. (2009) Airborne-Spaceborne DEM- and Laser Altimetry-Derived Surface Elevation and Volume Changes of the Bering Glacier System, 1972 through 2006. Journal of Glaciology, 55, 316-326. http://dx.doi.org/10.3189/002214309788608750

[20] Muskett, R.R. (2014) ICESat-Derived Elevation Changes on the Lena Delta and Laptev Sea, Siberia. Open Journal of Modern Hydrology, 4, 1-9. http://dx.doi.org/10.4236/ojmh.2014.41001

[21] Rosenqvist, A., Shimada, M. and Watanabe, M. (2004) ALOS PALSAR: Technical Outline and Mission Concepts. Proceedings of the 4th International Symposium on Retrieval of Bio- and Geophysical Parameters from SAR Data for Land Applications, Innsbruck, 16-19 November 2004.

[22] Shimada, M., Isoguchi, O., Tadono, T., Higuchi, R. and Isono, K. (2007) PALSAR CALVAL Summary and Update 2007. Proceedings of the IEEE International Geoscience and Remote Sensing Symposium, Barcelona, 23-28 July 2007, 3593-3596. http://dx.doi.org/10.1109/igarss.2007.4423622

[23] Rosenqvist, R., Shimada, M., Ito, N. and Watanabe, M. (2007) ALOS PALSAR: A Pathfinder Mission for GlobalScale Monitoring of the Environment. IEEE Transactions on Geoscience and Remote Sensing, 45, 3307-3316. http://dx.doi.org/10.1109/TGRS.2007.901027

[24] JAXA EORC (2008) ALOS Data Users Handbook, Revision C. Earth Observation Research and Application Center, JAXA, Japan. http://www.eorc.jaxa.jp/ALOS/en/doc/fdata/ALOS_HB_RevC_EN.pdf

[25] Sandwell, D.T., Myer, D., Mellors, R., Shimada, M., Brooks, B. and Foster, J. (2008) Accuracy and Resolution of ALOS Interferometry: Vector Deformation Maps of the Father's Day Intrusion at Kilauea. IEEE Transactions on Geoscience and Remote Sensing, 46, 3524-3534. http://dx.doi.org/10.1109/TGRS.2008.2000634

[26] Ebmeier, S.K., Biggs, J., Mather, T.A. and Amelung, F. (2013) Applicability of InSAR to Tropical Volcanoes: Insights from Central America. In: Pyle, D.M., Mather, T.A. and Biggs, J., Eds., Remote Sensing of Volcanoes and Volcanic Processes: Integrating Observation and Modelling, Geological Society, London, 15-37. http://dx.doi.org/10.1144/sp380.2

[27] Sandwell, D., Mellors, R., Tong, X., Wei, M. and Wessel, P. (2011) An InSAR Processing System Based on Generic Mapping Tools. Scrips Institution of Oceanography Technical Report, University of California, San Diego. http://topex.ucsd.edu/gmtsar/

[28] Chen, C.W. and Zebker, H.A. (2002) Phase Unwrapping for Large SAR Interferograms: Statistical Segmentation and Generalized Network Models. IEEE Transactions on Geoscience and Remote Sensing, 40, 1709-1719. http://dx.doi.org/10.1109/TGRS.2002.802453

[29] Wessel, P. and Smith, W.H.F. (1991) Free Software Helps Map and Display Data. EOS, Transactions of the American Geophysical Union, 72, 441-448. http://dx.doi.org/10.1029/90EO00319

[30] Wessel, P., Smith, W.H.F., Scharroo, R., Luis, J.F. and Wobbe, F. (2013) Generic Mapping Tools: Improved Version Released. EOS, Transactions of the American Geophysical Union, 94, 409-420. http://dx.doi.org/10.1002/2013EO450001

[31] Smith, R.G., Berry, P.A.M. and Benveniste, J. (2007) Representation of Rivers and Lakes within the Forthcoming ACE2 Global Digital Elevation Model. Proceedings of the ESA 2nd Space for Hydrology Workshop, 12-14 November 2007, Geneva. http://earth.esa.int/hydrospace07/participants/04_03/04_03_Smith.pdf

[32] Berry, P.A.M., Smith, R.G., Freeman, J.A. and Benveniste, J. (2008) Towards a New Global Digital Elevation Model. In: Sideris, M.G., Ed., International Association of Geodesy Symposia, Springer-Verlag, Berlin, 431-435. http://dx.doi.org/10.1007/978-3-540-85426-5 52

[33] Rexer, M. and Hirt, C. (2014) Comparison of Free High Resolution Digital Elevation Data Sets (ASTER GDEM2, SRTM v2.1/v4.1) and Validation against Accurate Heights from the Australian National Gravity Database. Australian Journal of Earth Sciences, 61, 213-226. http://dx.doi.org/10.1080/08120099.2014.884983

[34] Division of Oil and Gas (2008) Regional Geology of the North Slope of Alaska. Department of Natural Resources, State of Alaska, North Slope Oil and Gas Resources, Plate 2 of 4.

[35] Mull, C.G., Houseknecht, D.W., Pessel, G.H. and Garrity, C.P. (2004) Geologic Map of the Umiat Quadrangle, Alaska. US Geologic Survey, Scientific Investigations Map 2818-A, Department of Interior, Washington DC.

[36] Flores, R.M., Myers, M.D., Houseknecht, D.W., Stricker, G.D., Brizzolara, D.W., Ryherd, T.J. and Takahashi, K.I. (2007) Stratigraphy and Facies of Cretaceous Schrader Bluff and Prince Creek Formations in Colville River Bluffs, 
North Slope, Alaska. US Geological Survey, Professional Paper 1748, Department of Interior, Washington DC.

[37] Romanovsky, V.E., Smith, S.L., Christiansen, H.H., Shiklomanov, N.J., Streletskiy, D.A., Drozdov, D.S., Oberman, N.G., Kholodov, A.L. and Marchenko, S.S. (2013) Arctic Report Card: Update for 2012-Permafrost. NOAA Climate Program Office through the Arctic Research Program, Washington DC.

http://www.arctic.noaa.gov/report12/permafrost.html

[38] Muskett, R.R., Romanovsky, V.E., Cable, W.L. and Kholodov, A.L. (2015) Active-Layer Soil Moisture Content Regional Variations in Alaska and Russia by Ground-Based and Satellite-Based Methods, 2002 through 2014. International Journal of Geosciences, 6, 12-41. http://dx.doi.org/10.4236/ijg.2015.61002

[39] Arab-Sedze, M., Heggy, E., Bretar, F., Berveiller, D. and Jacquemoud, S. (2014) Quantification of L-Band InSAR Coherence over Volcanic Areas Using LiDAR and in Situ Measurements. Remote Sensing of Environment, 152, 202-216. http://dx.doi.org/10.1016/j.rse.2014.06.011

[40] Zebker, H.A. and Villasenor, J. (1992) Decorrelation in Interferometric Radar Echoes. IEEE Transactions on Geoscience and Remote Sensing, 30, 950-959. http://dx.doi.org/10.1109/36.175330

[41] Wei, M. and Sandwell, D.T. (2010) Decorrelation of L-Band and C-Band Interferometry over Vegetated Areas in California. IEEE Transactions on Geoscience and Remote Sensing, 48, 2942-2952. http://dx.doi.org/10.1109/TGRS.2010.2043442

[42] Asplin, M.G., Lukovich, J.V. and Barber, D.G. (2009) Atmospheric Forcing of the Beaufort Sea Ice Gyre: Surface Pressure Climatology and Sea Ice Motion. Journal of Geophysical Research, 114, Article ID: C00A06. http://dx.doi.org/10.1029/2008jc005127

[43] Liu, L., Zhang, T. and Wahr, J. (2010) InSAR Measurements of Surface Deformation over Permafrost on the North Slope of Alaska. Journal of Geophysical Research, 115, Article ID: F03023. http://dx.doi.org/10.1029/2009jf001547

[44] Liu, L., Schaefer, K., Zhang, T. and Wahr, J. (2012) Estimating 1992-2000 Average Active Layer Thickness on the Alaskan North Slope from Remotely Sensed Surface Subsidence. Journal of Geophysical Research, 117, Article ID: F01005. http://dx.doi.org/10.1029/2011jf002041

[45] Liu, L., Jafarov, E.E., Schaefer, K.M., Jones, B.M., Zebker, H.A., Williams, C.A., Rogan, J. and Zhang, T. (2014) InSAR Detects Increase in Surface Subsidence Caused by an Arctic Tundra Fire. Geophysical Research Letters, 41, 3906-3913. http://dx.doi.org/10.1002/2014GL060533 